tions of them-the one that they are mere coincidences, as was thought to be the case in similar outbreaks of pulmonary phthisis before the discovery of the tubercle bacillus; the other that they are due to an infective organism finding by chance in a given locality several persons of proper receptive capacity coincidently with a satisfactory means of distribution. Time alone will show which is the correct explanation, but such cases should be borne in mind, and every detail noted as it occurs. The cases are sometimes met with in a single house, sometimes in a group of neighbouring houses, sometimes in a part of a town or village, whilst sometimes an entire district may be temporarily affected. The greatest pains should be taken to ascertain whether in such outbreaks there is a single factor or a group of factors common to the whole of the persons attacked, and the outbreak should be examined on exactly the same lines as have yielded such good results in cases of typhoid, diphtheria, and other epidemic diseases.

Chaotic as are our present ideas in regard to the origin of cancer, we have good reason to hope that they may shortly be reduced to order. Feeble as is the evidence upon which the working hypothesis of the infectivity of the disease is based, it|is daily being strengthened by observations,-clinical, pathological, and statistical. There is no reason why the steady work done upon the origin of cancer should not be rewarded in the future with the same meed of success as in the past has attended that bestowed upon the larger animal parasites, for the study of bacteriology has given us new methods, and has enabled us to deal with much more minute objects than was formerly possible.

It appears in the light of our present knowledge that if an organism be the cause of cancer, it should be amcboid and spore-producing, spending a part of its life in damp earth and a part in epithelial cells. It should be extremely tenacious of life, and must have a long resting period though its spore-bearing time may be very short. Its effect upon epithelial cells would be rather to stimulate them and cause their amitotic division than to lead to their destruction, and this irritation of the cells might perhaps serve the secondary purpose of providing the complex proteid foods necessary for the growth of the organism.

I have brought this paper before you, gentlemen, in the hope that it may direct your attention to those points in connection with the cause of cancer, in which you are able to afford very material assistance at the expense of a very small amount of trouble.

I will therefore recapitulate the chief points in which you can render service by careful and accurate observation. The influence of heredity should be ascertained in every case of cancer, the inquiries being made in reference to the collateral as well as to the lineal descent. A vague statement that such and such a relative died of cancer is insufficient; the exact variety of cancer should be ascertained, the duration of the disease, and if possible the seat of the primary growth and of the secondary deposits; in women, too, it should be noted whether pregnancy has any bearing upon its commencement or upon its progress. The family diathesis on the parents' side is easily noted in a single word. The occurrence of such innocent tumours as wens, warts, and fibromata in other members of the family is also ascertained without difficulty, and when they occur, the ages at which they grew and the position which they occupied should also be recorded. It is still an open question whether gout, rheumatism, and other manifestations of an arthritic diathesis are in any way associated with cancer, and there are some who maintain that in a community where flesh is sparingly consumed the largest meat eaters are the most likely to be affected with cancer. It would therefore be well to consider these points. Those who reside in districts where cancer is especially frequent should bear in mind the work done by Haviland, and should ascertain in each house where cancer has occurred whether the soil is water-logged either generally as a result of floods, or locally from damp and wet cellars. All local outbreaks of cancer should be examined as to their cause in the manner usually adopted to ascertain the source of any of the more common epidemic diseases, and an endeavour should be made to ascertain what factor in the life or surroundings is common to each of the persons affected. It might be well also for those who are interested in the subject to tabulate the domestic remedies recommended and used for the cure of cancer, as their number is undoubtedly very numerous. An infusion of the common dead nettle taken to the extent of half a pint a day, and also used as an enema, has been recently and strongly recommended to $m e$ as an infallible cure for encephaloid cancer of the rectum, and its good results have been pointed out in an individual case. It is interesting as a piece of folk-lore, but it is otherwise useless. Lastly, we require more information as to the frequency with which cancer occurs in those countries where women are secluded, and this can readily be obtained for us by those newly admitted members of our Association who are privileged to enter the zenanas and harems of the world.

\section{A CASE OF MALIGNANT DISEASE OF THE} THORACIC MEDIASTINAL GLANDS :

\section{Dilatation of the Drscending Aorta, Marked} Cardiac Intermission and Bradycardia.

BX

ARTHUR E. SANSOM, and FRED. TRESILIAN, M.D., F.R.C.P. M.D., M.s.

MR. T., aged 45, stated that he used to have "bilious headaches " very badly when a boy. He had syphilis-a chancre followed by sore throat-twenty-two years ago. He had not had either acute rheumatism or influenza. About six years before he came under observation he began to have attacks of "dimness of sight, with forked-lightning flashes when he closed his eyes." These were usually followed by frontal headache, which did not last long. These attacks (undoubtedly migrainous in nature) became slightly altered, and the headaches were attended with numbness and weakness in either arm, preceded by a mistiness of vision and pain, which might occur in either temple, but most frequently in the right. These were sometimes attended with a difficulty of speech-a hesitation in getting hold of the right word. He lately went to a Hydropathic Institution, where he was told that he was suffering from "nervous exhaustion, with enlargement of the liver, which latter organ was $1 \frac{1}{2}$ inch larger than normal." He came away with his liver reduced to almost its normal size. He had also been treated recently for " suppressed gout."

About a month before he came under our treatment (in August, 1894) he became subject to rushes of blood to his head, which were quite sudden and of only momentary duration, with giddiness and a tendency to faint. He thinks he never lost consciousness, but on one occasion he dropped his gloves, his umbrella, and a parcel during an attack. He passed an enormous quantity of urine at night.

He had had a cough for about a month, which occurred sometimes in severe paroxysms, and with dyspnce. He had also experienced, especially on waking, a loud buzzing noise in both ears, lasting for about an hour. His sight had bfen very weak of late. He had pains in his back and legs. He noticed that his heart lately occasionally stopped beating, and that his pulse was slow; and sometimes palpitation, with a quickened pulse, occurred. There were frequent attacks of giddiness.

He had a sallow complexion. The pupils were almost pinhole, and reflex was feeble to light. There was marked inspiratory stridor, which was more noticeable after talking. There was no paralysis of the vocal cords, as was verified on two or three occasions. The fundi oculorum were normal, and the urine normal. The pulse was 38 to 40 in the minute, the beats being in groups, mostly of two or of five, with a prolonged pause, well shown in the sphygmographic tracing annexed, furnished by Dr. Sansom. I had never met

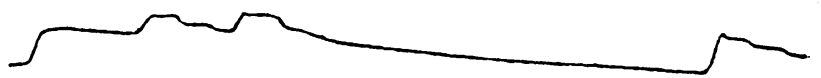

with such a long pause. The action of the valves was apparently normal. There was occasional hæmoptysir, the 
blood being mixed with saliva or mucus. There was sometimes a profuse quantity of saliva tinged with blood. The right lung was normal. There was dulness over the left lung, and the respiratory murmur was feeble. Dr. Sansom saw him the day after this, August 28th, and supplied the following notes:

"There is evidence of hypertrophy of the left ventricle. The heart's apex is felt and mapped out beneath the seventh rib and costal cartilage. There is a systolic murmur of slight intensity, audible at the aortic cartilage, and in the third and fourth left intercostal spaces close to the sternum. There is no evidence of dilatation of the right cavities. The irregularities of the heart's rhythm are very peculiar. After a group of three pulsations-on some occasions of two-there occurs a long pause. This pause, as timed carefully from the sphygmogram, lasts just five seconds. Its time duration is rather less than that occupied by the group of three pulsations. In linear measurement the former was 56 millimetres, the latter 32 millimetres. It is concluded that this extreme bradycardia must be due to an irritating lesion of the vagus, the problem being how the irritation was produced. The breath sounds are notably diminished over the upper lobe of the left lung. There is marked inspiratory stridor."

September 21st. He complained of shooting pains about his body, especially in the upper part of the left arm, also in the chest, thighs, and right arm, which pains were sharp and momentary.

October 21st. Pain in the chest continued; he had had some hæmoptysis. There was dulness, on percussion over the great part of the left side of the chest to the line of the sternum, and also dulness behind. The heart's impulse was most distinct to the left of the nipple towards the axillary line. The breath sounds over the left side were feeble, especially over the upper part. There was pain. with difficulty in swallowing, referred to about the mid sternum. He had had only one slight rush of blood for a fortnight. The inspiratory stridor was not so distinct. The pulse was 44. The pupillary reflex was better. Knee-jerks were normal.

October 25 th. The pulse was 46 and much more regular in rhythm; there were occasional groups of two or three beats. Dulness still existed over the left side, with the exception of an area of resonance over the site of the pulmonary valves. Here also there was a rough systolic bruit.

October 29th. Dysphagia was very troublesome for solids. Fearing that there was some intrathoracic tumour, possibly either a malignant growth or an aneurysm, another consultation was held with Dr. Sansom, who on October 30th gave his opinion in favour of an aneurysm of the aorta pressing upon the csophagus and the root of the left lung. There were no signs of any outward determination of the sac towards the chest wall, and there was considerable displacement of the impulse of the heart towards the left, almost to the axillary line. He was ordered rest in bed, with light diet, and iodide of sodium gr. 25 thrice a day.

December 12 th. The dysphagia had been very troublesome of late, but was now better for fluids. The cough was better, being only occasional and not severe. There was no dyspncea when lying quiet in bed, but there was if he made any kind of exertion. The pain in the chest was better, and also the rushes of blood. Palpitation still occurred at night. The pulse was 48 to 50 , and was variable. Sometimes it was regular for thirty-six or forty-eight hours, and at other times it relapsed into groups of three or four. Change of position altered both its rhythm and rate, and after an attack of palpitation it would beat regularly at 50 for a long time. The bruit over the chest was less distinct. The heart's beat was more tranquil, and the impulse had receded more towards the normal position. The dulness over the chest was still the same. The inspiratory stridor was not so distinct.

January 14th, 1895. A great change for the worse had taken place within the last few days. There was now considerable dyspnœa, mostly inspiratory. The pulse was 60 , running up to 69 . The urine was very scanty, and loaded with lithates and there was marked hoarseness. He was very weak, and complained of pain at the epigastrium and at the posterior lobe of the left lung. The dulness extended across the sternum to the right. 'There was exaggerated respiration over the right lung, and forcible pulsation in the epigastrium (right ventricle?). There was a creaking sound over the ribs at the left lateral base, and over the precordium with each impulse of the heart.

January 15th. There was considerable dyspnca. The pulse was 60, and quite regular. Cardiac displacement was marked to the right of the sternum, and percussion dulness also: He died quietly that night. There was no hæmorrhage at the end. With the exception of the pulsation at the epigastrinm the day before he died, which was due to the heart being gradually displaced to the right by effusion into the left pleura, there had been no evidence of any pulsation or pulsating tumour over any part of the chest.

The necropsy was made the next evening. The body was emaciated. There was a large quantity -8 to 10 pints-of fluid, slightly tinged with blood, in the left pleural cavity. There was also a small quantity-about 10 ounces-in the right pleural cavity. With the fluid from the left side there were some old blood clots. The left lung was entirely collapsed, occupying the upper and posterior part of the cavity, and lying upon the spine. The upper part of the lung was hard and dense, the lower portion was in a condition of hypostatic congestion. The whole left lung was no larger than two closed fists. The right lung was, hypertrophied, and in a partially emphysematous condition; it was deeply congested. In the posterior mediastinum was a large mass of new growth, quite fibrous and hard, which filled up the posterior mediastinum, and enclosed all structures in its vicinity. The root of the left lung was especially involved; the growth having completely occluded the left bronchus, and compressed the pulmonary artery and veins. There were trabeculous extensions of the growth into the adjacent part of the left lung. The pneumogastric nerves and the œsophagus - down to the diaphragm - and the trachea were surrounded by the growth. The descending aorta was also implicated, being somewhat constricted below, and dilated anove the constriction. The growth was perfectly hard and fibrous, and no ulceration or breaking down had occurred that could be seen. It was firmly adherent to all its surroundings, to the spine and the diaphragm. and involved and compressed in its growth all structures at the back of the thorax. The heart was hypertrophied and slightly fatty, the hypertrophy being most marked in the right ventricle. The liver was very much enlarged from venous congestion. The spleen was the same. Nothing abnormal could be found anywhere else.

It is in the highest degree probable that the remarkable bradycardia and the grouped beats with the long pauses between were due to an irritant lesion of the vagi, for the necropsy showed that these nerves in a portion of their course were surrounded by the malignant growth.

\section{CASE OF SEROUS EFFUSION INTO THE PLEURA OF EIGHTEEN MONTHS' DURATION,}

TREATED BY REPEATED PARACENTESIS, AND SUBSEQUENTLY BY

FRER INCISION, PROBABLY TUBERCULOUS IN ORIGIN, AND ASSOCIATED WITH CHRONIC ASCITES ; RECOVERY

COMPLETE, WITH RE-EXPANSION OF THE LUNG AND LITTLE CONTRACTION OF THE SIDE.

By SA MUEL WEST, M.D., F.R.C.P. Assistant Physician to St. Bartholomew's Hospital ; Senior Physician to the Royal Free Hospital, etc.

Is June, 1893, I was asked to see Miss B. P., aged 31, whose abdomen and right side of the chest had been full of fluid for more than twelve months. The object was to obtain my opinion as to whether anything could be done to relieve her.

It appeared that until September, 1891, she had been in perfect health, and was active, energetic, and athletic. She then began to feel weary and to lose her usual energy. In October she became troubled with severe pains in the abdomen. which came. on and off. both night and day. She had 1 kead before the Medical sociely of London. 